Revista de Estudios Histórico-Jurídicos

[Sección Historia del Pensamiento Jurídico]

XXXVI (Valparaíso, Chile, 2014)

[pp. $467-479$ ]

\title{
JOHN LOCKE Y LA LEY DE LA MODA. DE LA TEOLOGÍA A LA SOCIOLOGÍA DE LA LEY NATURAL
}

[John Locke and the Law of Fashion.

From Theology to Sociology of the Natural Law]

\author{
Juan Fernando Segovia* \\ Universidad de Mendoza, Argentina
}

\section{RESUMEN}

Locke trató de la ley natural en varios escritos y desde luego en el Ensayo sobre el entendimiento humano, que han sido poco estudiados y cuyas contradicciones con su Ensayos sobre la ley de la naturaleza no han sido notadas. El trabajo pretende dilucidar qué lugar ocupa la ley natural en la clasificación de las leyes del Ensayo y esclarecer que vínculos hay entre la ley divina, la ley civil y la ley de la moda o reputación. Luego, el trabajo trata de realizar una apreciación crítica de la doctrina de Locke.

Palabras Clave

Ley natural - Ley de la moda - Ética consensual-Relativismo moral - Positivismo jurídico-político.

\begin{abstract}
Locke wrote about natural law in many texts, and of course in An Essay Concerning Human Understanding, which have not been studied widely and which contradictions with his Questions Concerning the Law of Nature have not been noted. This work intends to clarify what is the place for the law of nature in the classification of the laws in the Essay and to enlighten what are the relationships among the divine law, the civil law and the law of fashion or reputation. Then, we seek to carry out a critical analysis of Locke's doctrine.

\section{KeYwords}

Natural law - Law of fashion - Consensual ethics -Moral relativism - Legal political positivism.
\end{abstract}

ReCibido el 21 de octubre de 2013 y ACEPTADo 26 de julio de 2014

* Profesor de la Universidad de Mendoza. Investigador del CONICET. Domicilio postal: Los Álamos 358 - Mayor Drummond - C.P. 5507 Luján de Cuyo, Mendoza, Argentina. Correo electrónico: segojuan@gmail.com 


\section{INTRODUCCIÓN}

1. John Locke (1632-1704) compuso un único escrito especial sobre la ley natural, que permaneció inédito hasta mediados del siglo pasado ${ }^{1}$. Sin embargo, esos Ensayos sobre la ley de la naturaleza se consideran inacabados y, por lo mismo, no alcanzan a exponer más que aquello que al autor preocupaba entonces sobremanera: cómo se conoce la ley natural. Los inconvenientes y problemas ${ }^{2}$ que dejó Locke planteados e irresueltos en tal ocasión no serán remediados -al menos en términos filosóficos o teológicos- en sus obras posteriores. El mismo Locke declara, al comienzo del segundo de los Tratados sobre el gobierno civil, que está más allá de sus propósitos profundizar en los detalles de la ley de la naturaleza ${ }^{3}$. No debería esperarse, en consecuencia, nada diferente a lo ya dicho en el ensayo de $1664^{4}$; al contrario, habría que aguardar sólo por las derivaciones políticas de la teoría expuesta en aquellos Ensayos.

Los Tratados, como insistentemente repiten los estudiosos de Locke, persiguen una finalidad política antes que filosófica; de modo que Locke presentará -especialmente en el segundo- a la ley natural en una nueva dimensión, pues hay acuerdo en que su doctrina política está guiada por ciertas creencias basadas en una evidencia probable, limitada por ciertos principios fundamentales, provenientes de una moralidad teológicamente estructurada ${ }^{5}$.

${ }^{1}$ LocKe, John, Essays on the Law ff Nature (1664, reimpresión, New York, 1970).

${ }^{2}$ Entre otros, señalamos: la oscuridad de la ley de la naturaleza, la relación de ésta con el interés personal, la existencia de sanciones y recompensas que generan la obligación de obedecerla, la esencia inviolable de la ley natural, etc. Aun son pertinentes las críticas y observaciones de Strauss, Leo, Locke's Doctrine of Natural Law, en The American Political Science Review, 52 (1958) 2, pp. 490-501. Hay versión española: STRAUSS, Leo, La ley natural en la teoría de Locke, en El MISMO, ¿Qué es filosofía politica? (Madrid, 1970), pp. 268-300.

${ }^{3}$ Locke, John, Two Treatises of Government (1690, reimpresión, London, 1768), lib. II, cap. $2^{\circ}, \$ 12$. p. 203.

${ }^{4}$ Podría concluirse que el pensamiento de Locke sobre la ley natural no necesitaba de ulteriores elaboraciones epistemológicas para ser usado como la premisa mayor de su teoría política. Así Seliger, M., Locke's Natural Law and the Foundation of Politics, en Journal of the History of Ideas, 24 (1963) 3, p. 340. Efectivamente, Locke agrega a continuación de las palabras antes citadas: "Sin embargo, es cierto que hay una ley de este tipo [natural] y que es tan inteligible y tan evidente a una criatura racional y un estudioso de ella, como las leyes positivas de las comunidades políticas. Mejor dicho, quizá tan evidente, tanto como la razón es más fácil de entender que los caprichos e intrincados estratagemas de los hombres, persiguiendo intereses ocultos y contrarios a los escritos; por lo que está fuera de duda que una gran parte de las leyes civiles solo son justas en cuanto están fundadas en la Ley de la naturaleza, por la que han de regularse y ser interpretadas". Locke, John, Two Treatises, cit. (n. 3), lib. II, cap. $2^{\circ}, \mathbb{1} 12$, p. 203. Es decir que, de un modo indirecto, confirma la trascendencia casi definitiva de lo considerado en los Ensayos y ratifica el modo de resolver las cuestiones allí planteadas. De hecho, es la tesis de von LEYDEN, W., "Introduction”, en LocKe, J., Essays, cit. (n. 1), pp. 80-82.

${ }^{5}$ Cf. Ashcraft, Richard, Locke's Political Philosophy, en Chappell, Vere (editor), The Cambridge Companion to Locke (Cambridge, 1999), p. 226. Para Tully ha sido mérito de Locke el abordar los problemas de los derechos y del poder político en términos no históricos sino de ley natural. Cf. Tully, James, A Discourse on Property: John Locke and his Adversaries (Cambridge, 1983), cap. $1^{\circ}$. 
2. Ahora bien, contemporáneo de la publicación de los dos Tratados, es el Ensayo sobre el entendimiento humano, en el que Locke mantiene las principales ideas de los Ensayos sobre la ley de la naturaleza, pero avanza unos pasos más adelante, pasos que deberían ser ponderados cuidadosamente para entender el rol que corresponde a la ley natural en la vida social y política. Luego, es una simplificación pasar de los Ensayos a los Tratados sin tener en cuenta lo que Locke afirma sobre la ley moral en el libro II del Ensayo.

No obstante la importancia del tema, la mayoría de los especialistas en Locke apenas sí se detienen a considerar la cuestión de la ley natural en el Ensayo, lo que hasta cierto punto es entendible, pues son más los problemas que allí se plantean al intérprete que las soluciones que brinda.

\section{LA Ley nATURAL EN EL “ENSAyo” DE Locke}

1. Tratándose principalmente de un texto de epistemología o teoría del conocimiento, el Ensayo aborda casi de soslayo la cuestión que estamos elucidando, pero anticipa aspectos del desarrollo de su teoría ética que apenas sí despuntaban en la obra anterior sobre la ley de la naturaleza. Así, por caso, aunque reitera su metodología epistemológica, afina la perspectiva individualista-racionalista que invalida la tradición y la educación como fuentes legítimas de conocimiento ${ }^{6}$. Además elabora su concepción de la moral desde una perspectiva claramente hedonista según la cual el bien y el mal son intercambiables con el placer y el dolor (mejor dicho: con lo que procura placer y con lo que provoca dolor, respectivamente ${ }^{7}$ ), queriendo dotar a la ciencia de la moral de una certidumbre matemática ${ }^{8}$, coincidente con su proyecto de una ética deductiva -aunque siempre dependiente de lo que cada uno entienda por felicidad-, referida a la voluntad y la libertad de un agente libre?.

2. Viniendo a nuestro asunto, Locke retoma la idea de la necesidad de un legislador soberano como fundamento de toda $l_{\text {ey }}{ }^{10}$, a la que define como el decreto

${ }^{6}$ Locke, John, An Essay Concerning Human Understanding, lib. I, cap. $4^{\circ}, \$ 23$, en EL MISMO, The Works of John Locke (1690, reimpresión, London, 1823), I, pp. 78-79: "En la medida que consideramos y alcanzamos la verdad y la razón por nosotros mismos, en esa medida poseemos un conocimiento real y verdadero." Por lo tanto, la ley de la naturaleza no es algo impreso en el hombre sino que llegamos a conocerla aplicando nuestras facultades. LocKE, John, An Essay, cit. (n. 6), lib. I, cap. $2^{\circ}, \$ 13$, en The Works, I, p. 20. Esta es la misma doctrina de los Ensayos ampliada y confirmada: la ley natural no se conoce sino sensiblemente, pues no es ella revelada ni está impresa en el alma, no se la aprehende por la enseñanza, la tradición ni el consenso. LOCKE, John, Essays, cit. (n. 1), capítulos $3^{\circ}, 4^{\circ}$ y $5^{\circ}$.

${ }^{7}$ Locke, John, An Essay, cit. (n. 6), lib. II, cap. $20^{\circ}, \$ 2$; lib. II, cap. $21^{\circ}, \$ \$ 42,43,52$, 62; lib. II, cap. $28^{\circ}, \$ 5$; etc. (The Works, I, pp. 231, 262-263, 263-264, 270-271, 279, y II, p. 97). Sobre el hedonismo egoísta de Locke, Darwall, Stephen, The British Moralists and the Internal "Ought": 1640-1740 (Cambridge, New York \& Melbourne, 1995), cap. 6, pp. 149 ss.

${ }^{8}$ Locke, John, An Essay, cit. (n. 6), lib. IV, cap. 4º $\$ 7-9$ (The Works, II, pp. 387-390).

${ }^{9}$ Locke, John, An Essay, cit. (n. 6), lib. I, cap. III, \$6 (The Works, I, pp. 38-39).

${ }^{10}$ Locke, John, An Essay, cit. (n. 6), lib. I, cap. 4 $\$ 8$ (The Works, I, p. 60): "sin la noción de un legislador es imposible tener una noción de una ley y de una obligación de observarla”. Fue el argumento central de la obra anterior, LocKE, John, Essays, cit. (n. 1), cap. I. 
de ese legislador que establece recompensas y castigos para su cumplimiento o su inobservancia, según el caso ${ }^{11}$. Es decir, en toda ley el elemento esencial es la voluntad de coacción por la que se premia o castiga ${ }^{12}$, porque lo conveniente o lo inconveniente operan naturalmente, espontáneamente, sin necesidad de ley alguna.

Hay un aspecto en el Locke introduce una novedad si tenemos en cuenta los anteriores Ensayos, y es en la clasificación de las leyes: conserva la ley divina (o eterna) y también la ley civil (o humana), pero, en lugar de la ley natural, invoca ahora "la ley de la opinión o reputación"13, también llamada ley de la moda o filosófica.

3. ¿Qué ha ocurrido con la ley de la naturaleza? La insólita trilogía de leyes que Locke introduce en el Ensayo ha dado lugar a diversas opiniones sobre el territorio que ocupa la ley natural. En una posición extrema, se ha dicho que no existe ley natural dado que en el Ensayo no hay lugar para ella ${ }^{14}$, lo que es así en un sentido extremadamente literal. Próxima a ésta es la tesis según la cual la ley de la opinión es la sanción humana de los preceptos establecidos en la ley divina, sin que deba hacerse mención de la ley natural ${ }^{15}$. Podría argüirse también que, conforme al modo de pensar protestante, la ley natural ha sido incorporada a la ley divina ${ }^{16}$, esto es, devenido miembro de la ley divina positiva. Esta posibilidad es cierta, pero no parece que Locke haya intentado unificar ambas leyes. Cabría entender, en cuarto lugar, y en franca oposición a las anteriores, que la ley de la opinión es la ley moral sustitutiva de la divina ${ }^{17}$, esto es, que la ley natural está confundida con la ley de la opinión, se ha mimetizado en ésta y, por su carácter secular, se ha desligado de la ley eterna ${ }^{18}$.

Frente a la diversidad de opiniones, nos parece que lo primero que se debe tomar en consideración es que, en el contexto de la exposición lockeana, la ley natural, como norma de la moral, ha perdido autonomía conceptual. Ha perdido autonomía nominal, pues no se la menciona expresamente. Pero también ha perdido autonomía conceptual, en el sentido de que ha sido diluida o metamorfoseada. La licuación o transfiguración de la ley natural ocurre de tres modos: en parte en la ley divina y, en parte, en la ley de la opinión, aunque también en la ley civil, pues estas tres leyes juzgan sobre la rectitud moral ${ }^{19}$. Expliquémonos.

${ }^{11}$ Locke, John, An Essay, cit. (n. 6), lib. II, cap. 28º $\$ 5$ (The Works, II, p. 97).

${ }^{12}$ Locke, John, An Essay, cit. (n. 6), lib. II, cap. $28^{\circ}, \$ 6$ (The Works, II, p. 97): "allí donde suponemos una ley se supone además una recompensa o un castigo anejos a esa ley".

${ }^{13}$ Locke, John, An Essay, cit. (n. 6), lib. II, cap. 28, \$7 (The Works, II, p. 98).

${ }^{14}$ Laslett, Peter, "Introduction", en Locke, John, Two Treatises of Government (14a edición, Cambridge, 2003), p. 81.

${ }^{15}$ Forster, Greg, John Locke's Politics of Moral Consensus (New York, 2005), pp. 200 s.

${ }^{16}$ Schneewind, J. B., Locke's Moral Philosophy, en Chappell, Vere (editor), cit. (n. 5), p. 205, entiende que la verdadera ley moral es la ley divina.

${ }^{17}$ Es la afirmación de STRAUSS, Leo, Natural Right and History ${ }^{7}$ (1950, reimpresión Chicago \& London, 1971), pp. 212-214, 229-230; y ZuCKERT, Michael, Launching Liberalism. On Lockean Political Philosophy (Lawrence, University Press of Kansas, 2002), pp. 147 ss.

${ }^{18}$ Que es también la tesis de KoselleCK, Reinhart, Crítica y crisis del mundo burgués (1959, reimpresión, Madrid, 1965), como se verá más adelante.

${ }^{19}$ Locke, John, An Essay, cit. (n. 6), lib. II, cap. $28^{\circ}, \S 13$ (The Works, II, p. 104). 
4. En un comienzo, la regla del bien moral es establecida por la ley divina, promulgada ya por la naturaleza ya por la revelación, pues, de acuerdo a Locke, nadie puede negar el derecho de Dios a establecer lo bueno y lo malo para sus creaturas y, en consecuencia, fijar los deberes y los pecados que acarrean la felicidad o la desgracia en virtud del Todopoderoso ${ }^{20}$. Pero la moralidad también corresponde a la ley humana, en cuanto juzga de las acciones criminales y establece recompensas y castigos en atención a "las vidas, las libertades y los bienes" de quienes viven bajo esa ley ${ }^{21}$. Parecería, entonces, que la ley natural (si se considera que está mentada como ley de la opinión) juega un papel intermedio y silencioso entre las leyes divina y humana.

Sin embargo Locke da una vuelta de tuerca al asunto: como la ley divina califica en términos de pecados y deberes, y la ley civil lo hace en términos de crímenes e inocencia, la que con propiedad es la medida de la virtud y del vicio es la ley filosófica, de la opinión o la moda. De los vicios y las virtudes de modo general, es decir, "por naturaleza", juzga la ley divina; mas en los casos particulares, es decir, "en cada país y sociedad", corresponde hacerlo a la ley filosófica, que amerita las acciones que gozan de reputación o merecen repudio. De modo que, según Locke, "por lo tanto, la medida de lo que en todos lados se llama virtud y vicio es esa aprobación o reprobación, elogio o censura, que, por un tácito y secreto consenso, se establece por sí misma en las diversas sociedades, tribus y conjunto de hombres en el mundo, en virtud de la cual las variadas acciones adquieren crédito o descrédito entre ellas, según el juicio, las máximas o la moda de cada lugar”22.

¿Por qué es así? La respuesta de Locke es tan simple como torpe, aparentemente. Pues - dice- habiendo cedido los hombres, al constituir la sociedad, el derecho a emplear todas sus fuerzas, han conservado, sin embargo, "el poder de pensar bien o mal, de aprobar o desaprobar los actos de aquellos con quienes viven o tratan, y por esa tal aprobación o reprobación establecen entre ellos mismos lo que considerarán virtud o vicio" 23 . Por un lado, entonces, la ley filosófica resulta producto

${ }^{20}$ Locke, John, An Essay cit. (n. 6), lib. II, cap. $28^{\circ}, \$ 8$ (The Works, II, p. 98). YolTON, John, Locke on the Law of Nature, en The Philosophical Review, 67 (1958) 4, pp. 485-486, cita una carta de Locke a Tyrrel, de 4 de Agosto de 1690 -el mismo año del Ensayo-, en la que aquél dice a su amigo que la ley de la naturaleza es una rama de la ley divina.

${ }^{21}$ Locke, John, An Essay, cit. (n. 6), lib. II, cap. 28, \$9 (The Works, II, pp. 98-99).

${ }^{22}$ Locke, John, An Essay, cit. (n. 6), lib. II, cap. XXVIII, $\$ 10$ (The Works, II, p. 99).

${ }^{23}$ Locke, John, An Essay, cit. (n. 6), lib. II, cap. 28, $\$ 10$ (The Works, II, p. 99). Es el argumento protestante sobre la incoercible libertad de conciencia, que estaba ya en Spinoza: existe en el hombre un derecho natural, que no puede abdicar y tampoco enajenar, de usar la inteligencia, imprescriptible facultad de la Naturaleza consistente en "razonar libremente las cosas", el libre derecho "de juzgar por sí mismo", que hace a cada individuo "dueño de sus pensamientos". DE SPINOZA, Benedict, Theological-Political Treatise (1670, reimpresión, Cambridge \& New York, 2007 ), cap. $20^{\circ}, \$ 2,3,8$, pp. $250-251$ y 253 . En Locke también hay un razonamiento similar: afirmada la libertad de conciencia, que es sin duda el más importante derecho individual -aun cuando se la restrinja a la libertad de culto-, se sigue la libertad de creencia, porque "si podemos decir abiertamente la verdad, como deben hacerlo los hombres entre sí, ni los paganos ni los mahometanos ni los judíos deberían ser excluidos de los derechos civiles del Estado a causa de su religión”. LoCKE, John, A Letter Concerning Toleration (1690, reimpresión, 1823), en The Works, cit. (n. 6), VI, p. 52. 
de la razón individual aplicada a la moral; mas, por otro lado, la experiencia y la observación demuestran que ese criterio individualista coincide generalmente con la regla invariable de lo bueno y lo malo fijada por la ley divina, probándose así el acuerdo entre los preceptos de Dios y los sentidos, entre la razón y el interés propio de los individuos ${ }^{24}$. Es así que se debe predicar la racionalidad de la ley moral filosófica.

5. Nada más simple, entonces, que asimilar la ley moral (la ley de la naturaleza) al juicio u opinión públicos en tanto que están ilustrados por una idea de lo bueno y lo malo según los decretos divinos. Porque hay una correspondencia entre la razón humana y la voluntad de Dios en torno a los principios de la moralidad; aun en tiempos de corrupción de las costumbres, "los límites verdaderos de la ley de la naturaleza, que debe ser la regla de la virtud y del vicio, fueron prácticamente preservados" 25 . Desde ya aparece una dificultad -que Locke sortea artificiosamente-, y es que esta ley carecería de legislador, porque no es ni Dios ni la autoridad civil o política; por tanto ha de establecerse, mejor dicho, suponerse, que es una ley tácita producto de la auto-legislación.

Es cierto, admite Locke, que cuando ha afirmado que "la ley por medio de la cual los hombres juzgan de la virtud y del vicio, no es otra cosa sino el consentimiento de los hombres particulares, que no tienen autoridad suficiente para hacer una ley", parecería haberse olvidado de su propio concepto de ley que reclama del poder para hacerla efectiva ("a power to enforce it"); pero no es así, pues la alabanza y la censura, el elogio y la deshonra ("commendation and disgrace") tienen tal poder sobre los hombres que "la mayor parte de ellos se gobierna principalmente, si no únicamente, por esta ley de la moda; de manera que quienes lo hacen conservan la reputación de quienes frecuentan, aun con poco respeto de las leyes de Dios o de los magistrados" 26 . Y en el seguir o no la ley de los filósofos encuentran los hombres también la recompensa o el castigo, pues nadie puede eludir "el castigo de la censura y de la aversión [que se imponen] a quienes ofenden la moda y la opinión de sus compañeros, y de aquellos ante quienes por sí mismo desea recomendarse" 27 .

Es así como, finalmente, la ley de la naturaleza se mimetiza con la opinión pública o las costumbres aprobadas por una sociedad, ley de la moda que, en virtud de la racionalidad humana, jamás se aparta totalmente de la ley divina ${ }^{28}$; $y$ que, en tanto juzga sobre el honor de las personas que viven en sociedad, posee

${ }^{24}$ Locke, John, An Essay, cit. (n. 6), lib. II, cap. XXVIII, $\$ 11$ (II, p. 103). La idea de un Ser Supremo añadida a la idea del hombre como ser racional constituyen el fundamento de la moral que puede, por lo mismo, convertirse en ciencia capaz de demostración. Locke, John, An Essay, cit. (n. 6), lib. IV, cap. $3^{\circ}, \$ 18$ (The Works, II, p. 368).

${ }^{25}$ Locke, John, An Essay, cit. (n. 6), lib. II, cap. 28, \$ 11 (II, p. 103).

${ }^{26}$ Locke, John, An Essay, cit. (n. 6), lib. II, cap. 28, $\$ 12$ (The Works, II, pp. 103-104). Repárese en la afirmación: "little regard the laws of God, or the magistrate".

${ }^{27}$ LocKe, John, An Essay, cit. (n. 6), lib. II, cap. XXVIII, $\$ 12$ (The Works, II, p. 104).

${ }^{28}$ Esto hace decir a Yolton que Locke no se contradice con lo explayado en los Ensayos pues continúa manteniendo la ley moral ligada a la ley de Dios. Yolton, John W., A Locke Dictionary (Oxford - Cambridge, 1993), p. 121. 
el suficiente poder para elevar en prestigio a quienes la respetan y abajar en la honra a los que la conculcan.

\section{APRECIACIÓN CRÍTICA}

1. La innovación de Locke tiene grandes consecuencias en la historia de las doctrinas sobre la ley natural y en aspectos particularmente históricos de la ética. Si observamos primero aquélla cuestión, la doctrina de la ley de la moda u opinión produce un grave trastorno, pues se reduce la ley natural a un brazo de la ley divina -permaneciendo dentro de ella o subsumida en ella-, como también la empequeñece o anula el convertirla en medida de la moda, de la fama, de la opinión. Decimos reducir y anular porque, en verdad, carece de vigencia como ley. En todo caso, la ley natural está sometida en su cumplimiento ya a la conciencia individual del creyente, ya a las convenciones sociales que los diversos grupos adoptan aquí y ahora. Puede así adquirir una presencia mística, idealista o sociológica; ser la regla del corazón, de la mente o de los clubes.

Tampoco ha esclarecido Locke al vínculo entre la ley natural -entendida como ley de la moda- y la ley civil, pues no se dice que ésta sea una especificación de aquélla, es decir, que la inocencia o la culpabilidad positivas se correspondan al honor o la deshonra morales.

También el descuido de Locke en torno a la figura del legislador de la ley de la moda: si se lee con atención la explicación antes citada, se advertirá que el razonamiento en lugar de resolver el problema de la falta de un legislador, se endereza a la existencia de premios y castigos. Dado que éstos existen, luego debe haber algún legislador superior que los imponga. Pero se sigue sin saber quién es éste, salvo que, como dijimos, se trata de la sociedad misma como auto-legisladora.

Además, Locke no se ha ocupado en probar de qué manera el consenso generalizado acerca de la ley de la opinión conserva correlato con la ley divina (o la ley natural), pues lo que puede valer para un tiempo y un lugar-por ejemplo, las normas morales de la sociedad inglesa de su época- puede no valer en otro tiempo y en otro lugar, como ya quedó demostrado por el propio Locke en los anteriores Ensayos ${ }^{29}$. Es decir, no hay fundamento alguno que pueda sostener la derivación de la ley de la opinión de la ley de $\operatorname{Dios}^{30}$. Y, en consecuencia, si afirmamos que la moral está regida por la ley de la moda, no hacemos más que sincerar el convencionalismo y el relativismo éticos ${ }^{31}$.

${ }^{29}$ LOCKE, John, Essays, cit. (n. 1), cap. V.

${ }^{30}$ Colman, John, Locke's Empiricist Theory of the Law of Nature, en Anstey, Peter R. (editor), The Philosophy of John Locke. New Perspectives (London - New York, 2004), pp. 121-124, intenta explicar que esa relación existe a partir de la teoría del conocimiento de Locke, pues no existiendo ideas innatas sólo sabemos lo que Dios quiere de nosotros a partir de la experiencia. De todos modos, como la experiencia es tan distinta como hombres hay, según Locke, no se ve de qué modo escapar del círculo vicioso.

${ }^{31}$ Lo que es consecuente con el hedonismo de Locke: los hombres tienen diferentes gustos y placeres, "to different men, are very different things", afirma LocKE, John, An essay, cit. (n. 6), lib. II, cap. $21^{\circ}, \$ 55$ (The Works, I, p. 273). En consecuencia, "habiendo Dios creado seres humanos diferentes, la ley de la naturaleza tendría un contenido diferente”, según ratifica CoLman, John, 
2. En efecto, según ha observado Ayers, la ley de la reputación viene a fortalecer la idea de una moralidad no teísta, intuitiva o filosófica, aunque no deje Locke, de alguna manera, de radicarla en Dios, no obstante la relatividad y variabilidad de las humanas apreciaciones morales. Locke es ambivalente o ambiguo -según Ayers-, si no contradictorio - decimos por nuestra parte-, pues por un lado observa que la ley de la moda puede ir contra la ley divina (como en el caso del duelo, que ésta considera pecado pero que en una sociedad puede aprobarse como acto de coraje $^{32}$ ), y por el otro sugiere que puede haber coincidencia entre lo que dispone un legislador justo y benevolente con lo que acuerdan los hombres centrados en la estimación de sus propios intereses.

Viene aquí a cuento una idea que Locke desarrolla en su ensayo de 1706 Sobre la ética en general, en el que sostiene -en palabra de Ayers- que "la generalizada concepción de la ética como una ciencia adecuada a los filósofos proviene de una suerte de oscura $[\mathrm{dim}]$ apreciación de la ley de la naturaleza. Solamente porque los filósofos han fracasado en reconocer las reglas morales como mandamientos divinos, es que han sido capaces de apelar únicamente a las sanciones de la reputación o la desgracia, mientras que el contenido de los sistemas morales seculares ha sido restringido ya a la defensa de lo que tiende a la preservación de la sociedad, ya a la simple designación de las acciones que una sociedad particular aprueba o reprueba" ${ }^{33}$.

Es el mismo argumento que Locke expuso en los Ensayos sobre la ley de la naturaleza $a^{34}$, ahora usado para justificar el valor de las consideraciones de los moralistas sobre los borrosos meandros de la ley natural. “¿Para qué ha servido -afirma Locke- la mayor parte de los comentarios y disputas sobre las leyes de Dios y del hombre sino para hacer más dudoso su significado y complicar su sentido?" " 35 también, contra lo sostenido en esos primeros Ensayos, la regla de la moralidad queda ahora en manos del hombre común, a despecho de lo que el sabio o el interesado puedan indagar y determinar ${ }^{36}$.

cit. (n. 30), p. 120. Para este autor, los posibles conflictos se arreglan en la sociedad (política o pre-política), pero deja sin explicar cómo puede haber una ley moral de corte relativista intrínsecamente variable y qué criterio emplearía el poder político para dirimir los conflictos sociales que produce la variedad de gustos y disgustos. En todo caso, podría decirse que el hedonismo es el medio a través del cual el hombre es guiado hacia las normas morales relacionadas con la ley natural. ZuCKERT, Michael P., cit. (n. 17), pp. 29-30.

${ }^{32}$ Locke, John, An Essay, cit. (n. 6), lib. II, cap. $28^{\circ}, \$ 15$ (The Works, II, p. 106).

${ }^{33}$ Ayers, Michael, Locke. Epistemology and Ontology (London - New York, 2005), II, p. 153. Cf. Locke, John, Of Ethics in General (1706, reimpresión, 1858), en KING, Lord, The Life and Letters of John Locke with Extracts From his Journal and Common-Place Books (London, 1858), pp. 308-309. En el escrito de Locke sobre la educación aconseja que a los niños se los eduque, más que en satisfacer sus apetitos, en el "amor a la reputación” para que se vuelva habitual en ellos. Cf. Locke, John, Some Thoughts Concerning Education, en EL MISMO, The Educational Writings of John Locke (1693, reimpresión, Cambridge, 1922), sec. 185a , p. 151.

${ }^{34}$ LOCKE, John, Essays, cit. (n. 1), cap. VIII, dirigido contra Carneades.

${ }^{35}$ Locke, John, An Essay, cit. (n. 6), lib. III, cap. X, $\$ 12$ (II, p. 275).

${ }^{36}$ Locke, John, Essays, cit. (n. 1), p. 165: "si lo que es justo y legal tuviera que ser determinado por la manera en que viven los hombres, la rectitud e integridad moral no serían apreciadas”. Y agrega: “¿Qué inmoralidad no sería permitida, e incluso inevitable, si la ley nos 
3. Por otra parte, Locke no resuelve algunos inconvenientes que devienen de su propio concepto voluntarista de la ley ${ }^{37}$, centrado en la voluntad que se impone mediante la coacción ${ }^{38}$. En particular, el problema del consenso como medio de promulgación, que ya había rechazado en los primeros Ensayos ${ }^{39}$; además del anonimato del legislador, según se dijo. ¿Cómo podemos saber promulgada una ley que se legitima en un consenso que, según Locke, es tácito y discreto? Si es así, entonces hay una voluntad anónima que opera de legislador desconocido amparada en un consentimiento que se presume general. Pero no es más que un supuesto de Locke o, mejor dicho, una mistificación suya que sirve para validar la moral burguesa en ascenso ${ }^{40}$.

Aspecto histórico éste, pero que no quita importancia al asunto del consenso o del consentimiento, porque así como en el Ensayo es la fuente de la moralidad, en los Tratados adquirirá enorme trascendencia política. Es decir, en el escrito que consideramos queda ya delineado el consensualismo ético y jurídico-político como modalidad del positivismo en el que remata el iusnaturalismo racionalista. La introducción del consenso con carácter positivo está en contradicción con lo que Locke ha dicho en los Ensayos sobre la ley de la naturaleza y reiterado en el Ensayo sobre el conocimiento en general. ¿Cómo puedo conocer, en el sentido que lo entiende Locke, un precepto moral que se me manifiesta a través de los usos y las costumbres? Será un cocimiento falso, semejante al que se gana a través de la tradición, pero nunca un conocimiento racional personal, individual. ¿Cómo puede conocerse, entonces, la ley natural? O más categóricamente, ¿cuál es el fundamento de la moral? Pues habrá que decir que no queda otra alternativa que la reputación y la fama, que el obrar moral es el que sigue la moda, la opinión establecida.

4. No puede negarse que, aunque la ley de la moda carezca de legislador identificable (claro está que, en última instancia, Locke podría argüir que es Dios,

fuese dada por el ejemplo de la mayoría?” Empero, en un giro argumental (que va contra su crítica al innatismo como contra su rechazo a la idea de una ley moral impresa en el hombre), Locke acaba afirmando que esos principios morales pueden hallarse en el alma o la conciencia humana, en los innermost ways of thinking, es decir, las más íntimas o profundas opiniones o convicciones. LocKe, John, Essays, cit. (n. 1), p. 167.

${ }^{37}$ Sobre este aspecto hay una vasta bibliografía, pero puede consultarse OAKLEY, Francis, Locke, Natural Law and God-Again, en History of Political Thought, 18 (1997) 4, pp. 624-651; y WarD, W. Randall, Divine Will, Natural Law and the Voluntarism/Intellectualism Debate in Locke, en History of Political Thought, 16 (1995) 2, pp. 208-218.

${ }^{38}$ Locke, John, Essays, cit. (n. 1), p. 111, dice que "la ley de la naturaleza pueda describirse como un decreto de la voluntad divina, discernible por la luz natural, que nos indica qué está y qué no está en conformidad con la naturaleza racional, y, por esa razón, qué es lo obligatorio y qué es lo prohibido".

${ }^{39}$ LOCKE, John, Essays, cit. (n. 1), p. 151, afirma que la expresa promulgación es necesaria para "saber que hay, por parte de ese poder superior, una voluntad respecto a las cosas que han de ser hechas por nosotros".

${ }^{40}$ Porque la ley natural está al alcance de los simples e indoctos, de cualquier unscholastick Statesman. LocKe, John, An Essay, cit. (n. 6), lib. III, cap. 10, $\$ 9$ (The Works, II, p. 273). Sobre esta cuestión, véase WALDRON, Jeremy, God, Locke, and Equality. Christian Foundations of John Locke's Political Thought (Cambridge \& New York, 2002), cap. $4^{\circ}$. 
aunque de modo remoto o mediato) y su conocimiento no sea científico, ella sí posee poder coercitivo. En los anteriores Ensayos sobre la ley de la naturaleza, se daba por sentado -sin probarlo-que habiendo otra vida después de la muerte, la ley de la naturaleza debía ser respetada pues en aquella otra vida se aplicaban los castigos y las recompensas; en el Ensayo sobre el entendimiento humano, en cambio, la misma ley natural, convertida en ley filosófica, deriva hacia otro método de justificación: la ley de la moda aplica aquí y ahora las penas y los premios a los hombres, porque ella es la que distribuye los honores y las deshonras, las alabanzas y los bochornos. Esto es, de una sanción ultraterrena hemos venido a un castigo y a una recompensa mundanos.

En el Ensayo, después de insistir en que no hay ley sin sanciones, y que en el caso de la ley (divina) moral esas sanciones son aplicadas por Dios, Locke comenta de inmediato que "respecto de las penas que acompañan el quebrantamiento de las leyes divinas, algunos, quizá la gran mayoría, raramente reflexionan sobre ellas; y entre aquellos que sí lo hacen, muchos, a la vez que violan la ley, abrigan pensamientos de una reconciliación futura y enmendar la culpa por tal violación.” ${ }^{41}$ Esto quiere decir que las sanciones divinas son insuficientes para obligar a los hombres a obedecer la ley natural; debe existir, por tanto, alguna fuerza humana que los compela a ello. Aquí, en el Ensayo, es la ley de la moda; en el Segundo Tratado será el derecho de juzgar y castigar en el estado de naturaleza ("the executive power of the law of nature"), luego convertido en los poderes legislativo y judicial de la sociedad civil. De modo tal que la moral puede volverse cierta aunque, como hemos visto, al precio del voluntarismo, el convencionalismo y el relativismo.

12. La ya inarmónica teoría de la ley natural que Locke elaboró en los primigenios Ensayos queda más desarticulada aún con la introducción de la ley de la moda o de la reputación; sin embargo halla su justificación en el contexto histórico-político europeo que es el del ascenso de la burguesía. Con Hobbes -y también Spinoza- se había introducido una tajante separación entre la conciencia humana, como ámbito interior intangible, y el poder legal del soberano ${ }^{42}$; mas ahora con Locke la conciencia se expande y sale del interior humano para volverse conciencia social sobre las normas morales ${ }^{43}$, es decir, para convertirse en la misma ley moral. Visto en perspectiva histórica asistimos a un doble movimiento por el que la moral religiosa primero se repliega en la conciencia individual (Hobbes, Spinoza) para volver a desplegarse en la ley de la moda ahora como moral burguesa secular (Locke). "El veredicto de los ciudadanos -escribe Koselleck-, que se justifica a sí mismo como justo y verdadero, esto es, la censura, la crítica, se convierte en el poder ejecutivo de la nueva sociedad.”44

5. Pero, por lo mismo, no deja de ser una moral formal, carente de preceptos,

${ }^{41}$ LoCKE, John, An Essay, cit. (n. 6), lib. II, cap. XXVIII, $₫ 12$ (II, p. 104).

${ }^{42}$ Hobbes, Thomas, Leviathan, en El MISMO, The English works of Thomas Hobbes (1651, reimpresión, London, 1839), lib. I, cap. 15; lib. III, cap. 38, 40, etc., para la distinción entre una esfera interna y externa, los pensamientos interiores y las acciones exteriores. Cf. KOSELLECK, R., cit. (n. 18), p. 55, n. 52, para un amplio desarrollo.

${ }^{43}$ Es la tesis de Koselleck, R., cit. (n. 18), pp. 96 y ss.

${ }^{44}$ Koselleck, R., cit. (n. 18), p. 102. 
vacía de contenidos; pues si quisiera dárselos habría que recurrir a las cambiantes valoraciones de cada sociedad en cada momento. Locke compartía los hábitos morales burgueses de su tiempo; empero, si esa ley de la moda, de la opinión burguesa, e s la ley moral de toda sociedad en todo momento, entonces se vuelve relativa ${ }^{45}$. Lo que confirma lo antes dicho: alejándose cada vez más de la doctrina tradicional de la ley natural, Locke la hunde en el relativismo y en el convencionalismo. Que tenga que ver o no con los preceptos de la ley de Dios, es cosa que ahora a Locke no interesa ${ }^{46}$; la ley de la moda, como ley moral, y la ley divina, también como ley moral, coexisten sin delimitarse entre $s^{i 4}{ }^{47}$ Y es que no hay nada que delimitar. Como se expone en el segundo de los Tratados, a partir del contractualismo político, tras el pacto, para Locke no queda más que la ley positiva estatal que protege los derechos de la burguesía, que ha formado ese poder estatal a partir de su poder moral ${ }^{48}$.

\section{CONCLUSIÓN}

En síntesis, tal como se la presenta en el Ensayo, la ley natural ha quedado desligada de todo fundamento ontológico y teológico. Locke los ha sustituido por una regla moral puramente sentimental y convencional, asentada en la opinión, por

${ }^{45}$ En todo caso, es el resultado de la libre interpretación protestante de las Escrituras, esto es, del librepensamiento. "Es evidente -escribe Locke- que la enseñanza de la filosofía humana no es parte del diseño de la revelación divina; las expresiones de las Escrituras, al contrario, son por lo general más adecuadas a las percepciones vulgares de estas cuestiones y a las concepciones del lugar y el pueblo donde fueron expresadas." LOCKE, John, An Essay for the Understanding of the St. Pauls Epistles by Consulting St. Paul Himself, en A Paraphrase and Notes on the Epistles of St. Paul (1707, reimpresión, 1823), en El Mismo, The Works, cit. (n. 6), VIII, p. 21. Lo que viene en apoyo del cristianismo, que es la religión acomodada a las capacidades corrientes o vulgares, afirma LOCKE, John, The Reasonableness of Christianity, as delivered in the Scriptures (1695, reimpresión, 1823), en El MISMO, The Works, cit. (n. 6), VII, p. 157.

${ }^{46}$ Como escribe Locke en el Ensayo, "la razón es la revelación natural", y debe usarse para "regular", es decir, juzgar, nuestro asentimiento a supuestas revelaciones sobrenaturales. En materias específicamente religiosas: "reason must be our last judge and guide in every thing". LOCKE, John, An essay, cit. (n. 6), lib. IV, cap. XIX, \14 (III, pp. 156-157). De ahí que la religión natural sea preferida a la revelada. LocKe, John, An Essay, cit. (n. 6), lib. III, cap. $9^{\circ}, \$ 23$ (The Works, II, p. 267). O que el cristianismo se convierta en una fe perfectamente racional, como sostiene en The Reasonableness of Christianity.

${ }^{47}$ Koselleck, Reinhart, cit. (n. 18), p. 103.

${ }^{48}$ No desconocemos que este punto es controvertible, pues las afirmaciones de Locke son ser ambiguas y contradictorias. A nuestro juicio -y nos sometemos a una discusión más amplia- hay una prueba suficiente de su positivismo: Locke sostiene que el papel del poder político-que tiene su origen en el pacto constitutivo de la comunidad-consiste en hacer leyes y establecer castigos para asegurar la protección o subsistencia de la sociedad civil. Locke, Two Treatises, cit. (n. 3), lib. II, cap. $15^{\circ}, \$ 171$, p. 350 : “but a power to make laws, and annex such penalties to them as may tend to the preservation of the whole, [...] And this power has its original only from compact and agreement and the mutual consent of those who make up the community". Lo que quiere decir que el contrato constitutivo de la sociedad y del gobierno hace nacer un poder político que, para hacer aplicable la ley de la naturaleza, debe reinterpretarla y reforzarla por medio de la ley humana. En consecuencia, Locke se convierte en iuspositivista por vía hermenéutica; así lo ha visto Castellano, Danilo, Constitución y constitucionalismo (Madrid, 2013), p. 70. 
un lado, y en los derechos naturales del hombre libre, del propietario, los derechos de la burguesía ${ }^{49}$. La opinión de la sociedad es la que establece la valoración moral de las conductas individuales y no hay nada más apreciado por el hombre que la consideración social ni nada tan despreciable como el repudio de la sociedad ${ }^{50}$.

La ley natural, en Locke, ha devenido en el registro sociológico de la moral media de una sociedad cualquiera, dejando de ser la ley ética universal de la doctrina católica. El iusnaturalismo lockeano del Ensayo remata en una ética positivista y sociológica, en tanto y en cuanto es la cambiante opinión pública, el parecer social voluble, el que fija la regla de la moralidad.

\section{BiBLIOGRAFÍA}

Ashcraft, Richard, Locke's Political Philosophy, en Chappell, Vere (editor), The Cambridge Companion to Locke (Cambridge, 1999).

Colman, John, Locke's Empiricist Theory of the Law of Nature, en ANSTEY, Peter R. (editor), The Philosophy of John Locke. New Perspectives (London - New York, 2004).

DARWALL, Stephen, The British Moralists and the Internal "Ought": 1640-1740 (Cambridge, New York \& Melbourne, 1995).

Forster, Greg, John Locke's Politics of Moral Consensus (New York, 2005).

HobBes, Thomas, Leviathan, en El MISMO, The English Works of Thomas Hobbes (1651, reimpresión, London, 1839).

KoselleCK, Reinhart, Crítica y crisis del mundo burgués (1959, reimpresión, Madrid, 1965).

Laslett, Peter, "Introduction", en LOCKe, John, Two Treatises of Government (14a edición, Cambridge, 2003).

LEYDEN, W., "Introduction", en LocKe, J., Essays on the Law of Nature (1664, reimpresión, New York, 1970).

LOCKE, John, A Letter Concerning Toleration (1690, reimpresión, 1823), en El MISMO, The Works of John Locke (1690, reimpresión, London, 1823), I.

LOCKE, John, An Essay Concerning Human Understanding, en EL MISMO, The Works of John Locke (1690, reimpresión, London, 1823), I.

LOCKE, John, An Essay for the Understanding of the St. Pauls Epistles by Consulting St. Paul Himself, en A Paraphrase and Notes on the Epistles of St. Paul (1707, reimpresión, 1823), en EL MISMO, The Works of John Locke (1690, reimpresión, London, 1823), VIII.

LOCKE, John, Essays on the Law of Nature (1664, reimpresión, New York, 1970).

${ }^{49}$ No hace falta recurrir a la conocida crítica marxista de, por ejemplo, MacPherson. Por caso, TAYLOR, Charles, Sources of the Self. The Making of Modern Identity (Cambridge: Mass., 1989), p. 240, ha avanzado la hipótesis que el enfoque ético de Locke era un claro respaldo al progresista (improver) serio, productivo y pacífico, cualquiera fuera su clase social, un enfoque contrario a la ética aristocrática, a la conciencia de casta buscadora de honor y gloria a través de la auto-exposición, como también a las virtudes guerreras. "Locke continuó y desarrolló más allá la inversión de la antigua jerarquía de valores que supuso la ética de la vida ordinaria".

${ }^{50}$ Otro punto en el que coincide con Hobbes, quien resalta la tendencia o el instinto natural del hombre a perseguir la gloria que sólo la concede el juicio de sus semejantes. HOBBEs, Thomas, cit. (n. 42), lib. I, cap. 10, pp. 74 y ss. 
LOCKE, John, Of Ethics in General (1706, reimpresión, 1858), en KInG, Lord, The Life and Letters of John Locke with Extracts From his Journal and Common-Place Books (London, 1858).

LOcke, John, Some Thoughts Concerning Education, en El mismo, The Educational Writings of John Locke (1693, reimpresión, Cambridge, 1922).

LOCKE, John, The Reasonableness of Christianity, as delivered in the Scriptures (1695, reimpresión, 1823), en EL MISMO, The Works of John Locke (1690, reimpresión, London, 1823), VII.

Locke, John, Two Treatises of Government (1690, reimpresión, London, 1768).

OAKLEY, Francis, Locke, Natural Law and God-Again, en History of Political Thought, 18 (1997) 4.

SchneEwInd, J. B., Locke's Moral Philosophy, en Chappell, Vere (editor), The Cambridge Companion to Locke (Cambridge, 1999).

Seliger, M., Locke's Natural Law and the Foundation of Politics, en Journal of the History of Ideas, 24 (1963) 3.

SPINOZA, Benedict, Theological-Political Treatise (1670, reimpresión, Cambridge \& New York, 2007).

STRAUSS, Leo, La ley natural en la teoría de Locke, en El MISMO, ¿Qué es filosofía política? (Madrid, 1970).

Strauss, Leo, Locke's Doctrine of Natural Law, en The American Political Science Review, 52 (1958) 2.

STrauss, Leo, Natural Right and History ${ }^{7}$ (1950, reimpresión, Chicago \& London, 1971).

TAYLOR, Charles, Sources of the Self. The Making of Modern Identity (Cambridge: Mass., 1989).

Tully, James, A Discourse on Property: John Locke and his Adversaries (Cambridge, 1983).

Waldron, Jeremy, God, Locke, and Equality. Christian Foundations of John Locke's Political Thought (Cambridge \& New York, 2002).

Ward, W. Randall, Divine Will, Natural Law and the Voluntarism/Intellectualism Debate in Locke, en History of Political Thought, 16 (1995) 2.

Yolton, John W., A Locke Dictionary (Oxford - Cambridge, 1993).

Yolton, John, Locke on the Law of Nature, en The Philosophical Review, 67 (1958) 4. ZuckerT, Michael, Launching Liberalism. On Lockean Political Philosophy (Lawrence,

University Press of Kansas, 2002). 
